\title{
Towards Direct Simulation of Future Tropical Cyclone Statistics in a High-Resolution Global Atmospheric Model
}

\author{
Michael F. Wehner, ${ }^{1}$ G. Bala, ${ }^{2}$ Phillip Duffy, ${ }^{3}$ Arthur A. Mirin, ${ }^{4}$ and Raquel Romano ${ }^{5}$ \\ ${ }^{1}$ Lawrence Berkeley National Laboratory, 1 Cyclotron Rd. MS50F, Berkeley, CA 94720, USA \\ ${ }^{2}$ Divecha Center for Climate Change, Center for Atmospheric and Oceanic Sciences, Indian Institute of Science, \\ Bangalore 560 012, India \\ ${ }^{3}$ Climate Central, Inc., 895 Emerson St., Palo Alto, CA 94301, USA \\ ${ }^{4}$ Lawrence Livermore National Laboratory, Livermore, 94551-0808, USA \\ ${ }^{5}$ Google, Inc., 1600 Amphitheatre Parkway, Mountain View, CA 94043, USA
}

Correspondence should be addressed to Michael F. Wehner, mfwehner@lbl.gov

Received 31 December 2009; Revised 14 April 2010; Accepted 22 April 2010

Academic Editor: Song Y. Hong

Copyright ( $\odot 2010$ Michael F. Wehner et al. This is an open access article distributed under the Creative Commons Attribution License, which permits unrestricted use, distribution, and reproduction in any medium, provided the original work is properly cited.

We present a set of high-resolution global atmospheric general circulation model (AGCM) simulations focusing on the model's ability to represent tropical storms and their statistics. We find that the model produces storms of hurricane strength with realistic dynamical features. We also find that tropical storm statistics are reasonable, both globally and in the north Atlantic, when compared to recent observations. The sensitivity of simulated tropical storm statistics to increases in sea surface temperature (SST) is also investigated, revealing that a credible late 21st century SST increase produced increases in simulated tropical storm numbers and intensities in all ocean basins. While this paper supports previous high-resolution model and theoretical findings that the frequency of very intense storms will increase in a warmer climate, it differs notably from previous medium and highresolution model studies that show a global reduction in total tropical storm frequency. However, we are quick to point out that this particular model finding remains speculative due to a lack of radiative forcing changes in our time-slice experiments as well as a focus on the Northern hemisphere tropical storm seasons.

\section{Introduction}

Hurricanes and tropical cyclones are arguably the most devastating meteorological events in both loss of human life as well as financial costs. Following the most active Atlantic hurricane season ever recorded in 2005 , the debate as to the influence a warmer climate might have on the statistics of tropical cyclones has become more urgent. If the frequency or intensity of such storms were to change, the impacts could be severe. The number of tropical cyclones has been remarkably stable since 1970 averaging about ninety storms globally per year $[1,2]$. No statistically significant trend in this number of tropical cyclones has been observed in the period 1970 to present [1]. However, there is evidence of significant trends in tropical cyclone intensity and duration over this period. Holland and Webster [3] found that the number of Atlantic tropical cyclones has increased in a statistically significant sense and Emanuel [4] has correlated increases in a hurricane power index with increases in North Atlantic sea surface temperatures. Elsner et al. [5] have found a twenty-six year positive trend in the maximum wind speeds of Atlantic storms in the 70th percentile and greater by an analysis of satellite records.

A causal connection between warming in the main cyclogenesis regions and human activities has been established to a high degree of statistical certainty $[6,7]$. Future warming in these regions where most tropical cyclones form is virtually certain. However, sea surface temperature is only one of several factors determining tropical cyclone formation and development. Vorticity, humidity, wind shear and moist instability conditions must also be satisfied in the cyclogenesis region $[8,9]$. Additionally, a disturbance such as an easterly wave must pass through the cyclogenesis region at a moment when all these conditions are satisfied 
for a tropical cyclone to form. Detection and attribution of changes in cyclogenesis factors other than sea surface temperatures have not been presently attained in a formal statistical sense. Progress in this regard is limited not only by climate model characteristics, including resolution, but also by long high quality observational records. Our confidence in climate models' ability to model future changes in these other factors is substantially lower than it is for temperatures [10].

The current generation of coupled global ocean atmosphere models prepared for the Fourth Assessment Report (AR4) of the Intergovermental Panel on Climate Change (IPCC) are too coarsely resolved to directly simulate tropical cyclones. Nonetheless, some models produce vortices resembling tropical cyclones and have been interpreted in that light [11-13]. The number of high-resolution simulations of tropical cyclone statistics is limited. An innovative approach to reduce the computational burden uses a limited area north Atlantic basin hurricane prediction system forced with the output from coarser global climate models [14-16]. However, computational capabilities have increased to the point where it is feasible to run global models at resolutions high enough to directly simulate some aspects of tropical cyclones. Oouchi et al. [17] integrated an atmospheric model at high-resolution (a spectral truncation of T959, approximately $20 \mathrm{~km}$ at the equator) and found that the model could simulate some aspects of tropical cyclone behavior realistically and ran it long enough to generate robust statistical information. Zhao et al. [18] integrated a four member ensemble of a $50 \mathrm{~km}$ global atmospheric model finding a strong correlation between north Atlantic sea surface temperature (SST) and tropical cyclone count consistent with observations. They also found that future north Atlantic tropical cyclone frequency was more dependent on changes in a relative SST index rather than on changes in SST itself. In this paper, we present results from another high horizontal resolution atmospheric general circulation model (AGCM) that we find realistically simulates some aspects of individual tropical cyclones.

The model used in this paper is the finite volume dynamics form of the Community Atmospheric Model version 2.2 (fvCAM2.2). The ability of the model to simulate tropical cyclones is dependent on horizontal resolution. Most of the results presented here are at a horizontal resolution of $0.5^{\circ} \times 0.625^{\circ}$, which is about $50 \mathrm{~km}$ at the equator. At this resolution, we performed a simulation of the period 19791996 to compare the model's tropical cyclone statistics with observations. We have also performed a short integration at $0.25^{\circ} \times 0.375^{\circ}$ and find that details of the individual tropical cyclones produced are yet more realistic than they are at the coarser resolution. A lower resolution simulation of the period $1979-1994$ at $1.0^{\circ} \times 1.25^{\circ}$ was also performed further demonstrating the effect of resolution on tropical cyclones. At all three horizontal resolutions, the vertical structure of the model is identical to the 26 layers as in the standard NCAR release of $2.0^{\circ} \times 2.5^{\circ}$ horizontal resolution. Also, in all experiments described here no tuning or other modifications to the physics parameterizations were imposed.
In Section 2, we present results from a model simulation of the recent past and compare model tropical cyclone statistics with observations. In Section 3, we present results from the model forced under a future climate change scenario to investigate the sensitivity of the model's tropical cyclone statistics to increases in sea surface temperature (SST). In the future scenario experiments, we alter only SST and do not alter the atmospheric greenhouse gas concentrations or other radiative forcing agents. One study [19] has examined this issue and found that both increases in SST and atmospheric $\mathrm{CO}_{2}$ concentration independently cause a reduction in total tropical storm frequency in a different model. The direct radiative forcing effect is not included in our experimental design. In Section 4, we conclude with a discussion of these results and comparison to other estimates of the changes in possible future tropical cyclone activity.

\section{2. fvCAM2.2: A Present Day Simulation}

fvCAM2.2 is an intermediate release version of the Community Atmospheric Model developed at the National Center for Atmospheric Research (NCAR). This particular version shares many similarities to the atmospheric component of the Community Climate System Model (CCSM3.0). The principal difference is that the solution of the dynamics equations is performed using a finite volume approach [2023]. Significant differences in the parameterization of subgrid scale processes include cloud microphysics and radiation processes (Collins, et al. 2006). We performed a simulation of the recent past following the standard Atmospheric Model Intercomparison Project (AMIP2) protocol [24] over the period 1979 to 1996. The ocean and sea ice in the AMIP2 protocol is treated as a lower boundary condition with specified time varying values and distributions. Monthly varying sea surface temperatures and sea ice extent fields were generated by the Program for Climate Model Diagnosis and Intercomparison (PCMDI) with their standard algorithm for this study [25]. Simulations were integrated at three different horizontal resolutions, $1.0^{\circ} \times 1.25^{\circ}, 0.5^{\circ} \times$ $0.625^{\circ}$ and $0.25^{\circ} \times 0.375^{\circ}$. The standard vertical resolution of 26 vertical layers in the public release version of the model was retained [26], as was the hydrostatic approximation. The actual code was closely related to the publicly released version of CAM2.2, with significant changes only to the parallel computing domain decomposition strategies [27]. These changes were necessary to permit the usage of large number of processors allowing the numerical integration to proceed in a tolerable amount of time.

2.1. Ability of fvCAM2.2 to Capture the Dynamical Features of Tropical Cyclones. At moderate to high horizontal resolutions, the model produces many incidences of high local vorticity. Many of these events are identified to have characteristics of tropical depressions, tropical cyclones, and even hurricanes. These events are self-initializing from the numerical algorithm itself without any artificial stimulus or external forcing and vary considerably in maximum wind 




Figure 1: Instantaneous mean sea level pressure (in color) and surface wind ( 10 meter) vectors (as arrows) of the strongest Atlantic tropical cyclone in the $0.5^{\circ} \times 0.625^{\circ}$ horizontal resolution AMIP simulation. Pressure in $\mathrm{hPa}$, the wind vector scale in miles per hour is to the left of the color bar.

speed, local pressure minima, vertical structure, and trajectory. In a lengthy climate simulation, it is not appropriate to attempt a comparison to any specific observed tropical storm, as individual weather events are not predictable after a few weeks due to the chaotic nature of the atmosphere [28]. Nonetheless, analysis of individual simulated events can reveal if the model produces some of the typical behaviors associated with real storms.

In Figure 1, the strongest Atlantic storm simulated at the $0.5^{\circ} \times 0.625^{\circ}$ horizontal resolution is shown just before it makes landfall. At the time shown, this storm is at its greatest intensity. The maximum surface wind speed (at 10 meters) is 116 knots ( 133 miles per hour) and the surface pressure at the vorticity center is $945 \mathrm{hPa}$, which occurred just prior to landfall. On the Saphir-Simpson scale, these values would categorize this simulated storm as a category 4 hurricane. Over the course of the event, it maintained category 1 hurricane status or greater for 5 days. The storm quickly lost strength as it crossed into Texas and dissipated in a few simulated days.

In addition to the high winds and low pressure centers, other features of the simulated storms offer additional realism. In Figure 2, the scalar surface $(10 \mathrm{~m})$ wind speed and surface pressure isobars of this same simulated storm are shown 12 hours prior to that shown in Figure 1. Also, the trajectory of the storm up until landfall is shown by the thick dashed line. When this storm passed over the Yucatan Peninsula, it weakened somewhat. Later as it passed into the middle of the Gulf of Mexico, it reorganized and became more symmetric in its surface pressure structure. Real tropical cyclones and hurricanes often exhibit stronger winds along the leading edge of the storm and weaker winds along the trailing edge. This is also evident in this and other simulated storms that are far from land. Note the asymmetry of the colors representing scalar wind speed but the symmetry of the isobars. Wind speed asymmetry of this sort is a dynamical consequence as the storm's rotational velocity and its translational velocity add to produce the net wind speed. It is reassuring that the model maintains this

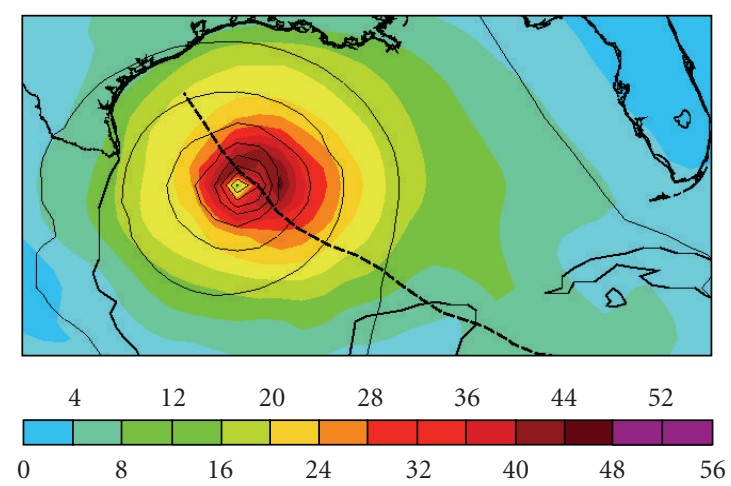

Figure 2: Instantaneous surface (10 meter) wind speeds (in color) and surface pressure (as isobars) for the same storm twelve hours earlier than in Figure 1. The storm center trajectory is shown as a thick dotted line. Units of wind speeds are $\mathrm{m} / \mathrm{s}$.

dynamical consistency. Note also that a hurricane eye (in velocity) is simulated although only a single velocity point on this Arakawa B-mesh [29] has near zero winds at this resolution.

The ability of the model to simulate tropical cyclones and hurricanes depends greatly on horizontal resolution. In general, as grid spacing is reduced, the strength of the most intense simulated storms increases. Hence, for a given magnitude, the number of simulated storms increases as horizontal resolution is increased. A twelve month simulation at a $0.25^{\circ} \times 0.375^{\circ}$ horizontal resolution was also performed. Although it is difficult to quantify how many more storms of a given intensity are simulated per year in this simulation due to the short integration period, several interesting storms of hurricane class are produced. Because of the higher fidelity, additional realism along with greater intensities is seen in these simulated storms. In Figure 3, the instantaneous precipitation is shown for a category 4 storm in September off the coast of the Bahamas simulated at the $0.25^{\circ} \times 0.375^{\circ}$ horizontal resolution. At the moment shown in Figure 3, the storm's maximum winds are 100 knots and the low pressure is $963 \mathrm{hPa}$. In this figure, the spiral and banded nature of intense precipitation exhibit some realism. Note especially the two intense precipitation bands exceeding $90 \mathrm{~mm} /$ day on either side of the hurricane center. Also note the long arms of precipitation extending towards the southeast and southwest. These features trail and rotate about the overall motion of the storm. However, even at this resolution there is no suppression of precipitation in the center of the eye of the storm. Although this storm is more compact than the less finely resolved storm in Figure 1, other storms at this resolution need not be so.

Strong tropical cyclones transport large amounts of heat energy from the ocean surface to high altitudes. Such an upper air temperature positive anomaly is one of the signatures of these events. In Figure 4, a vertical cross section of the air temperature of the storm in Figure 3 is shown at a slightly later time. This east-west cross section is a slice at $34.25^{\circ} \mathrm{N}$ across longitude lines intersecting the center of 


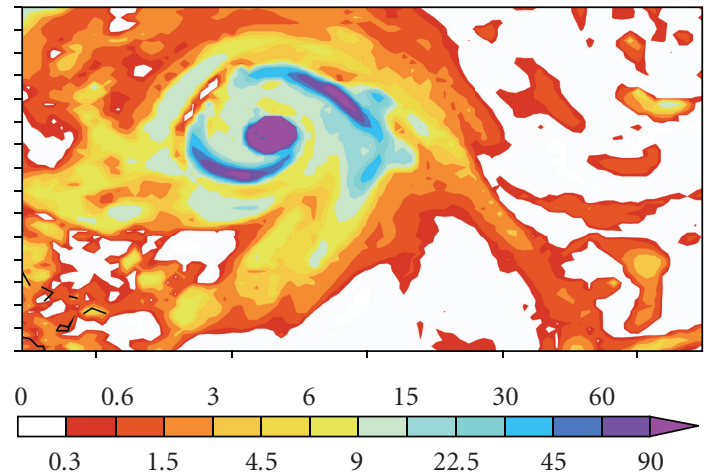

Figure 3: Instantaneous precipitation rates during an intense simulated North Atlantic hurricane at the $0.25^{\circ} \times 0.375^{\circ}$ horizontal resolution. Units are $\mathrm{mm} /$ day.

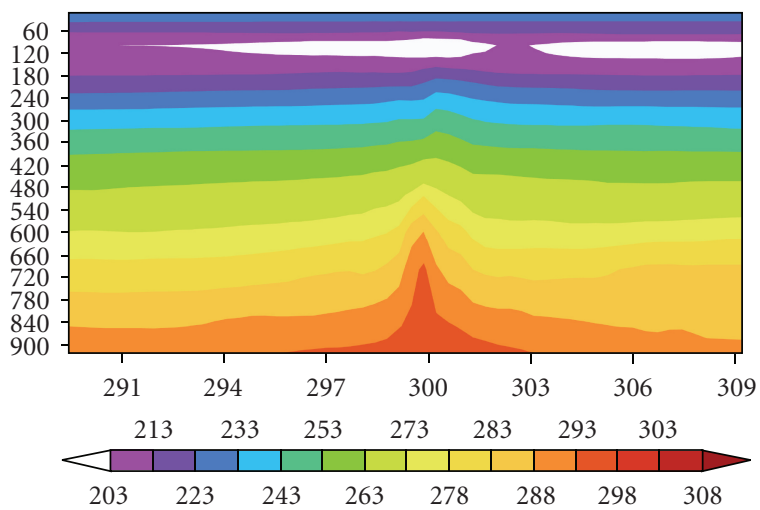

FIgURE 4: Vertical cross section of the air temperature at $34.25^{\circ} \mathrm{N}$ through the center of a simulated Atlantic tropical cyclone. Warm air is advected upwards inside the region of high vorticity. Air temperature units are Kelvin. Units of the vertical axis are hPa. The horizontal axis spans $290-309^{\circ} \mathrm{W}$.

the storm. The model exhibits realistic upwelling of heat from the ocean surface to higher altitudes as seen by the elevated temperatures near the storm center at $300^{\circ} \mathrm{W}$. The air temperature anomaly at $500 \mathrm{hPa}$ is up to $10 \mathrm{~K}$. At this point in time, the storm's northwestwards motion slightly tilts the tower of warm air to the east at the higher elevations.

\subsection{Ability of fvCAM2.2 to Capture the Statistical Features} of Tropical Atlantic Cyclones. Simulated storms such as the ones considered in the previous section occur spontaneously in the course of the integration long after any memory of the initial conditions is lost. Thus there is no direct relationship between these simulated storms and actual storms. However, data collected from the seventeen-year $0.5^{\circ} \times 0.625^{\circ}$ fvCAM2.2 AMIP simulation do permit a statistical comparison with actual storms. Identification of simulated tropical cyclones in this dataset was made by possible by running it through a tropical cyclone tracking program [15]. Developed at the Geophysical Fluid Dynamics Laboratory (GFDL), it produces storm tracks as well as summary statistics describing storm intensity by first finding colocated vorticity centers and local pressure minima, then identifying if the $300 \mathrm{mb}$ to $500 \mathrm{mb}$ average temperature is anomalously high relative to the surroundings and if the $1000 \mathrm{mb}$ to $200 \mathrm{mb}$ thickness is anomalous in that region. The tracking program was confined to ocean points to between $40 \mathrm{~S}$ and $40 \mathrm{~N}$. All other parameters used in the tracking program were the same as described in Appendix $B$ of Knutson et al. [15].

In the AMIP simulation, the $0.5^{\circ} \times 0.625^{\circ}$ fvCAM2.2 produced over the entire globe $165 \pm 8$ tropical storms per year of which 97 were of hurricane strength or greater and 23 were of intense hurricane strength. The model is overactive in its simulation of tropical storms when compared to the observational estimate of Frank and Young [2]. In that study, they estimate $87 \pm 8$ tropical storms of which $49 \pm$ 7 are of hurricane strength and $16 \pm 5$ are of intense hurricane strength. As is discussed in more detail below the model actually produces too few storms in the Atlantic basin. Hence, most of the tropical storms and nearly all of the simulated intense hurricanes were produced in the Pacific basin with these numbers significantly exceeding the observations. This overprediction of the ratio of Pacific to Atlantic tropical storms has been documented in a few other models [18].

A fifteen-year (1979-1994) AMIP-type simulation of fvCAM2.2 at $1.0^{\circ} \times 1.25^{\circ}$ permits a statement about the effect of horizontal resolution on tropical cyclone statistics. At this coarser resolution, the model produced a global average of only 52 tropical storms per year of which 25 were of hurricane strength. Although, the tropical storms are weaker than at the finer resolutions in general, the strongest storm in this simulation experienced maximum winds of 111 knots and a pressure minimum of $935 \mathrm{mb}$. However, only 11 tropical storms were produced in the north Atlantic basin over the entire simulation period.

Tropical storms in the North Atlantic basin are generally better observed than elsewhere with routine flights directly into them. This permits a much more detailed comparison in the North Atlantic of tropical cyclone statistics. The North Atlantic storm tracks produced from 1979 through 1996 by the model in the $0.5^{\circ} \times 0.625^{\circ}$ configuration are shown in upper panel of Figure 5. The observed storm tracks in this region over this period are shown for comparison in lower panel of Figure 5. The source of the observed storm data is the UNISYS Best Track database (available at http://weather.unisys.com/hurricane/). There are 173 actual storms and 83 simulated storms of tropical storm strength or greater identified by the tracking algorithm during this period in the North Atlantic basin. Most of the simulated storm tracks follow realistic paths despite biases in the mean atmospheric state (see the discussion in Section 4). However, we note that the model initiates too many tropical cyclones in the Caribbean and too few in the Eastern Atlantic.

Professor Gray and his team at Colorado State University have been statistically forecasting North Atlantic hurricane activity for many years $[30,31]$. The standards that the group applies to their forecast to measure success are also useful in assessing the ability of the model integration in this study to simulate tropical cyclone statistics. Professor Gray's 


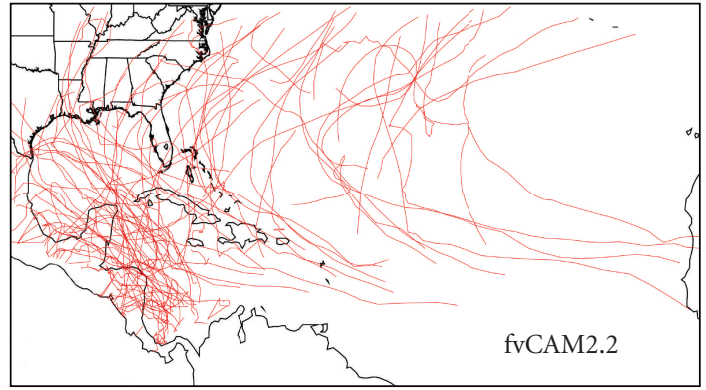

(a)

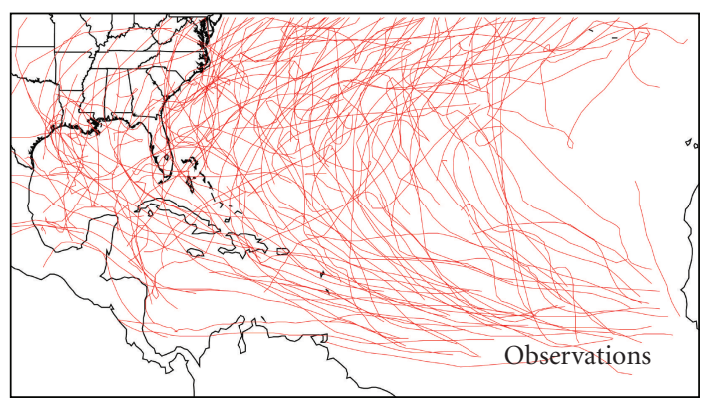

(b)

Figure 5: Simulated (a) and observed (b) tropical Atlantic cyclone storm tracks. The period is 1979 to 1996 and the model resolution is $0.5^{\circ} \times 0.625^{\circ}$.

group defines seven simple numbers describing the Atlantic hurricane season shown in Table 1 . The first four of them are easily comparable between the model and observations.

At the $0.5^{\circ} \times 0.625^{\circ}$ resolution, the model produced about half as many named tropical storms and a little less than half as many hurricanes in the north Atlantic basin than the observations as shown in Table 2. The total duration of the simulated named storms were shorter than the actual storms but the average simulated storm lasted about two days longer than the average real storm. At hurricane intensity, the model produced less total storm days with the average storm about half as long as the real storms over the 1979-1996 period.

As mentioned before, the ability to simulate high vorticity and associated winds is quite dependent on the model's horizontal resolution. Only three intense hurricanes (Category 3 or larger) in the north Atlantic basin were simulated over the seventeen-year simulation period. It is likely that a long simulation at higher horizontal resolution would produce a greater number of storms of hurricane intensity. Our simulation of fvCAM2.2 at the $0.25^{\circ} \times 0.375^{\circ}$ resolution could only be integrated for twelve months due to constraints on computer time allocations. However, two category 3 north Atlantic hurricanes were produced at this higher resolution with minimum pressures of 946 and $966 \mathrm{mb}$ with each storm exceeding 105 knots despite the relatively short integration period. The $0.5^{\circ} \times 0.625^{\circ}$ configuration of the model produced multiple storms of Category 3 and 4 in the Pacific basin in every simulated year of the AMIP integration. It never produced a category 5 storm in any ocean basin.

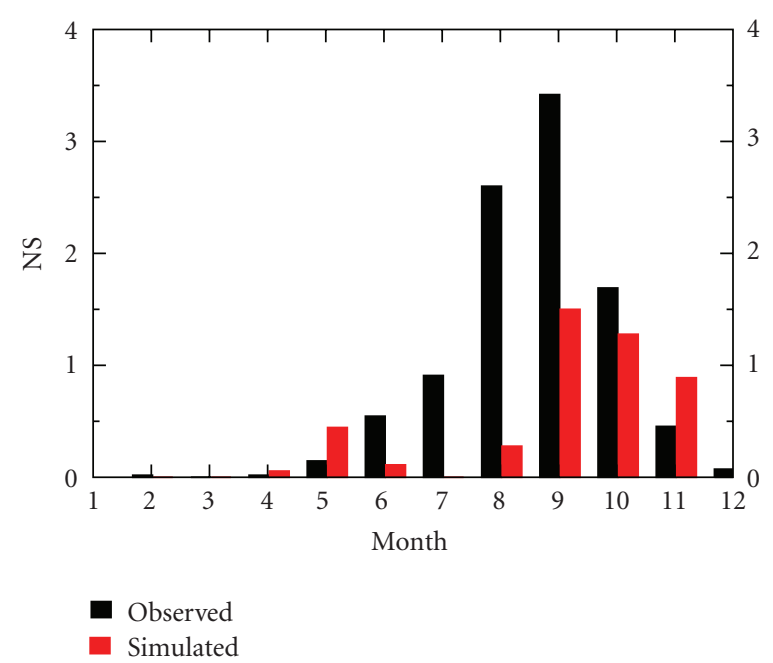

FIgURE 6: The average number of named Atlantic tropical storms per month in $0.5^{\circ} \times 0.625^{\circ} \mathrm{fvCAM} 2.2$ and observed.

Tropical storms in the Atlantic basin follow a distinct seasonal cycle dictated both by sea surface temperature and wind shear conditions. A comparison in Figure 6 of the seasonality of Atlantic tropical storms in the $0.5^{\circ} \times 0.625^{\circ}$ version of fvCAM2.2 and in the real world reveals that model is a bit late in its timing of the hurricane season. The period shown here is 1979 to 1996 . The model produces a few weak storms in months when there are practically no observed tropical cyclones (December through May). None of these form into hurricane strength.

Tropical cyclones exhibit significant interannual variability. Although the AMIP protocol specifies realistic monthly averaged sea surface temperatures for each year of the simulation, one should not expect the modeled tropical cyclone activity to agree with observations on a yearly basis because of the other factors important to cyclogenesis that are not constrained. In fact, the model does exhibit substantial interannual variability in the number of North Atlantic tropical storms as shown in Figure 7. Although the standard deviation of the observed and simulated annual storm counts are similar, the two-time series are not highly correlated (correlation factor $\sim 0.4$ ). Other models have exhibited a stronger relationship between interannual temperature variability and tropical storm count in the North Atlantic [18, 32].

\section{Future Changes in Simulated Tropical Cyclone Activity}

Historical changes in the intensity of tropical cyclones and hurricanes are strongly correlated with sea surface temperature (SST) changes in the cyclogenesis regions. While factors such as wind shear, moisture availability, and atmospheric stability also influence tropical cyclone genesis and evolution, there is emerging evidence that SSTs may play a dominant role in the late 20th century increase in intense hurricanes $[4,33]$. Attribution of recent increases in 
TABle 1: Professor Gray's seven hurricane summary statistics.

\begin{tabular}{lll}
\hline NS & Named Storms & Number of storms with winds exceeding 35 knots \\
NSD & Named Storm Days & Number of storm days with winds exceeding 35 knots \\
H & Hurricanes & Number of storms with winds exceeding 64 knots \\
HD & Hurricane Days & Number of storm days with winds exceeding 64 knots \\
IH & Intense Hurricanes & Number of storms with winds exceeding $96 \mathrm{knots}$ \\
IHD & Intense Hurricane Days & Number of storm days with winds exceeding 96 knots \\
NTC & Net Tropical Cyclone Activity & A relative measure of a given year's tropical cyclone activity. \\
\hline
\end{tabular}

Table 2: North Atlantic values of the first four of Professor Gray's hurricane summary statistics for the model and observations for the period 1979-1996.

\begin{tabular}{lcccc}
\hline & NS & NSD & H & HD \\
\hline Observations & 9.6 & 54.1 & 5.6 & 21.5 \\
fvCAM2.2 $0.5^{\circ} \times 0.625^{\circ}$ & 4.8 & 34.5 & 2.4 & 4.5 \\
\hline
\end{tabular}



FIgURE 7: The annual number of named Atlantic tropical storms (NS) per year produced by $0.5^{\circ} \times 0.625^{\circ}$ fvCAM2.2 compared to observations. The model and observed mean values are 4.6 and 9.6 and their standard deviations are 2.4 and 2.9, respectively.

cyclogenesis region SSTs to human-induced changes to the atmospheric composition suggests that future increases are highly likely $[6,7]$.

Three future scenarios defined in the IPCC "Special Report on Emissions Scenarios" were widely simulated by the global climate modeling community [34]. These scenarios span the range from minimal (A2), to moderate (A1B) and to aggressive efforts (B1) to reduce greenhouse gas emissions and are well represented in the publically accessible CMIP3 database of climate model integration [35].

In Figure 8, the predicted annual mean sea-surface temperature anomalies in the Atlantic Cyclogenesis Region (ACR) over the 21st century are shown. The ACR is the main development region for tropical cyclogenesis in the North Atlantic and spans $6^{\circ}-18^{\circ} \mathrm{N}$ by $300^{\circ}-340^{\circ} \mathrm{W}$. Results from simulations of 20 th century climate change experiment $(20 \mathrm{c} 3 \mathrm{~m})$ are also given. All modeled SST changes are the averages of multimodel ensembles. Observational SST changes are shown from two independent sources: ERSST, Extended Reconstructed SST data set [36] and HadISST, the Hadley Centre Sea Ice and SST data set [37]. Anomalies were calculated with respect to climatological annual means over $1900-1909$, and spatially averaged over $6^{\circ} \mathrm{N}-18^{\circ} \mathrm{N}, 60^{\circ} \mathrm{W}-$ $20^{\circ} \mathrm{W}$. Uncertainty in the model results is represented by the shaded envelopes, which are the $1 \sigma$ confidence intervals calculated across the ensemble of different models.

The prediction envelope encompasses a wide range of possibilities. The upper boundary, with SST increases of nearly $4.0^{\circ} \mathrm{C}$ by 2100 , is set by models with high climate sensitivities run with the A2 scenario. The lower boundary of the envelope, which is dictated by low-sensitivity models driven by the low emission rate B1 scenario, yields an SST increase of about $1.5^{\circ} \mathrm{C}$ by the end of the 21 st century. To put this increase in historical perspective, note that observed SST changes in the ACR range from 0.41 to $0.67^{\circ} \mathrm{C}$ over the 20 th century. Thus, even the lower boundary of the changes predicted to occur by 2100 represents an approximate doubling of the 20th century warming. Such an increase is well outside the range of model-based estimates of natural climate variability [6]. Similar behavior is seen in the main development region $\left(5^{\circ} \mathrm{N}-15^{\circ} \mathrm{N}, 180^{\circ} \mathrm{E}-130^{\circ} \mathrm{E}\right.$ designated below as PCR) for north Pacific tropical cyclones as well.

Note that the model-average SST changes in the A2, $\mathrm{A} 1 \mathrm{~B}$, and $\mathrm{B} 2$ scenarios are virtually identical until roughly 2030, and begin to diverge thereafter. The model-average warming over the next 20-30 years is nearly as large as the warming over the entire 20th century. By the end of the 21st century, the uncertainties associated with future greenhousegas emission rates are the largest contributor to the total prediction uncertainty, and there are large and statistically significant differences between the SST changes in the three scenarios. The ensemble-mean SST changes in 2100 range from 2.0 to 3.5 Kelvin. Such large increases would be truly unprecedented if realized.

In view of the historical relationship between cyclogenesis region temperatures and hurricane intensity [38], these projections of future cyclogenesis region SST changes motivate an investigation of potential changes in future tropical cyclone statistics by direct simulation. To investigate the sensitivity of the tropical cyclone statistics to increases in SST, we performed a second numerical experiment of two ensembles. In this set of simulations, we integrated an ensemble of fifteen simulations of the late 20th century 


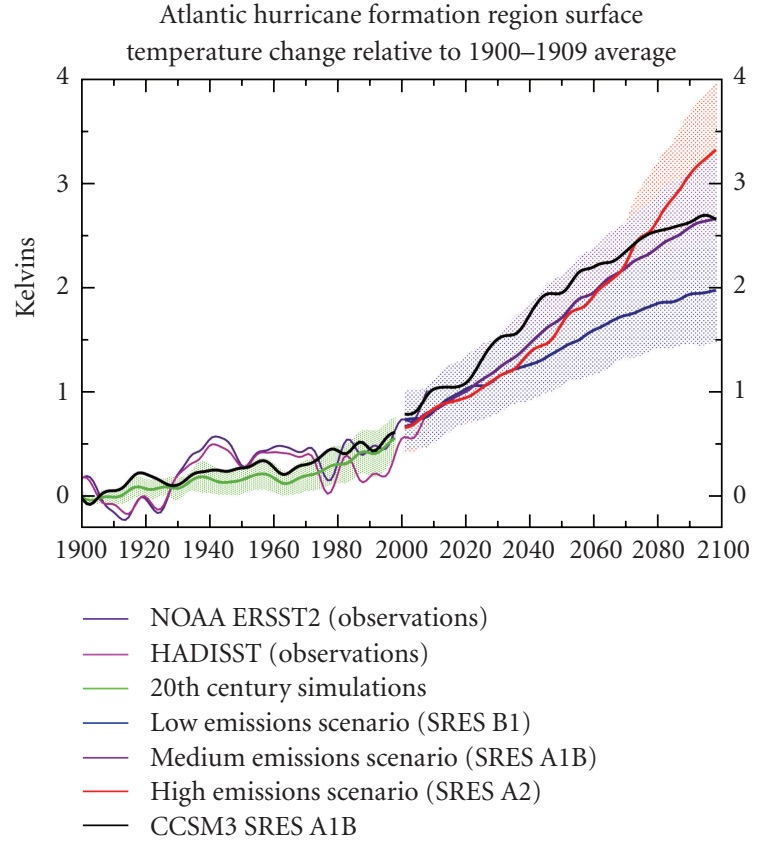

Figure 8: Modeled and observed annually averaged SST changes over the Atlantic cyclogenesis region. Model results are multi-model averages for the 20th and 21st centuries. Observed changes are for the 20th century only. All anomalies were defined relative to climatological means over 1900-1909. The shaded envelopes are the $1 \sigma$ confidence intervals calculated across the ensemble of simulated SST changes from different models. All data were smoothed by application of a 13-point binomial filter. The amplitude of simulated and observed SST variability over the 20th century is not directly comparable because simulated changes are averaged over realizations and models, thus damping climate noise. The CCSM3.0 result is shown for reference.

using the 1990-1999 climatological monthly SST values. The annual cycle was retained in this averaged surface forcing. A second ensemble of fifteen integrations was completed with only the SSTs changed to represent a future climate state. The SST change was constructed by adding the monthly average SST change predicted over 2090-2098 from an ensemble of eight realizations of CCSM3.0 forced under the A1B future scenario to the 1990-1999 climatological monthly SST. CCSM3.0 was chosen as the closest related model to fvCAM2.2 and its 2090-2098 average change over the Atlantic cyclogenesis region is 2.65 Kelvin. The solid black curve in Figure 8 shows the ACR response of CCSM3.0 relative to the other CMIP3 models. The spatial structure of the predicted SST change was retained in the construction of the future temperature forcing. Each member of the ensemble was initialized with slightly different initial conditions leading to statistically identical but randomly distributed realizations of the model climate. Also, as our original intent was to focus on the Atlantic basin, the simulations spanned a six-month period from July 1 to December 31 , in order to increase the number of Atlantic hurricanes produced. However, the results found are interesting for other ocean basins and we will discuss them here as well.
The initial conditions for both the future and past ensembles were chosen from the AMIP simulation described in the previous section. To remove the effect of these initial conditions, we discarded the first simulated month (July) from our analysis allowing the model to generate statistically identical independent realizations [28]. We also discarded the last month (December) of each simulation to ensure a uniformity of the output data, as a few runs did not complete the last few days due to computer hardware issues. In the AMIP experiment, the model averaged 66.8 tropical storms across the globe with winds exceeding 33 knots during the August through November period. The 1990-1999 ensemble of this sensitivity experiment averaged 62.7 such storms during these months. This difference is within both the interannual standard deviation of the AMIP simulation and the interrealization standard deviation of the 1990-1999 ensemble of the sensitivity experiment. Hence, we are comfortable that the choice of the time averaged surface forcing in the sensitivity experiment produces representative tropical cyclone statistics.

A comparison of the 1990-1999 ensemble with the A1B 2090-2099 ensemble reveals a dramatic increase in the number of tropical storms with winds in excess of 33 knots. Figure 9 shows this increase globally, hemispherically and in the ocean basins with tropical cyclone activity. Because the analysis is confined to the August through November period, most of the storms are located in the Northern Hemisphere. Statistical confidence in these changes is high both in the Northern Pacific and in the North Atlantic basins. Changes in tropical storm count are also statistically significant in the Southern Hemisphere, although the analysis period is out of phase with most of the tropical storms over this part of the ocean. A summary of the tropical storm counts represented by Figure 9 is shown in Table 3 . The null hypothesis that there is no difference between the number of "named" tropical storms in the two ensembles may be rejected with a confidence level of $99.9 \%$ or higher in all basins based on Student's test statistic.

Not only does the number of "named" storms increase when the model is forced with the higher A1B emissions scenario SSTs, the strongest storms get stronger. The average maximum wind speed of the strongest storm in each realization increases from 113 knots to 119 knots while the average minimum pressure in those storms decreases from $938 \mathrm{mb}$ to $931 \mathrm{mb}$. Figure 10 shows an increase in each category of the Saffir-Simpson Hurricane Scale when the SSTs are increased. The null hypothesis of no change in the number of storms in each of these categories may be rejected with high confidence except for that of Category 2 hurricane intensity. Table 4 summarizes the changes in tropical storm number as a function of intensity.

\section{Discussion}

4.1. The Relationship of Simulated Future Tropical Cyclone Statistics to Large-Scale Climatological Features. We have demonstrated that the simulated tropical cyclones statistics produced by one particular model, fvCAM2.2, exhibit a 
TABLE 3: Average number of tropical storms with wind in excess of 33 knots during the August-November period simulated in fvCAM2.2 as shown in Figure 9. Percent change is shown in the 4th column relative to the 1990-1999 ensemble average. Student's test statistic, calculated with 14 degrees of freedom is shown in the 5 th column. The last column shows the level of confidence for the rejection of the null hypothesis of no change in the number of tropical storms.

\begin{tabular}{|c|c|c|c|c|c|}
\hline & $\begin{array}{l}\text { Present no. of tropical } \\
\text { storms }\end{array}$ & $\begin{array}{l}\text { Future no. of tropical } \\
\text { storms }\end{array}$ & Percent change & Student's test statistic & $\begin{array}{c}\text { Statistical significance } \\
\text { of change }\end{array}$ \\
\hline Global & 62.7 & 87.7 & $40 \%$ & 11.5 & $>99.9 \%$ \\
\hline $\begin{array}{l}\text { Northern } \\
\text { Hemisphere }\end{array}$ & 51.9 & 71.6 & $38 \%$ & 11.5 & $>99.9 \%$ \\
\hline $\begin{array}{l}\text { Southern } \\
\text { Hemisphere }\end{array}$ & 10.7 & 16.1 & $51 \%$ & 4.7 & $>99.9 \%$ \\
\hline North Pacific & 40.0 & 51.2 & $28 \%$ & 7.5 & $>99.9 \%$ \\
\hline $\begin{array}{c}\text { North } \\
\text { Atlantic }\end{array}$ & 5.1 & 8.6 & $70 \%$ & 5.6 & $>99.9 \%$ \\
\hline South Pacific & 0.7 & 2.6 & $250 \%$ & 4.9 & $>99.9 \%$ \\
\hline Indian Ocean & 12.5 & 18.3 & $47 \%$ & 5.0 & $>99.9 \%$ \\
\hline
\end{tabular}

TABLE 4: The average number of tropical storms across the globe during the August-November period as characterized by the Saffir-Simpson scale simulated by fvCAM2.2 as shown in Figure 10. Percent change is shown in the 4th column relative to the 1990-1999 ensemble average. Student's test statistic, calculated with 14 degrees of freedom is shown in the 5th column. The last column shows the level of confidence for the rejection of the null hypothesis of no change in the number of tropical storms. The "present" ensemble is forced with 1990-1999 sea surface conditions. The "future" ensemble is forced with sea surface conditions representative of the SRES A1B scenario at the end of the 21 st century.

\begin{tabular}{|c|c|c|c|c|c|}
\hline & $\begin{array}{l}\text { Present no. of tropical } \\
\text { storms }\end{array}$ & $\begin{array}{l}\text { Future no. of tropical } \\
\text { storms }\end{array}$ & Percent change & Student's test statistic & $\begin{array}{c}\text { Statistical significance } \\
\text { of change }\end{array}$ \\
\hline All named storms & 62.7 & 87.7 & $40 \%$ & 11.5 & $>99.9 \%$ \\
\hline Tropical storm & 25.8 & 40.9 & $59 \%$ & 6.7 & $>99.9 \%$ \\
\hline Category 1 & 20.1 & 24.3 & $21 \%$ & 3.04 & $>99.5 \%$ \\
\hline Category 2 & 8.3 & 9.5 & $15 \%$ & 1.09 & $<90 \%$ \\
\hline Category 3 & 7.9 & 10.3 & $29 \%$ & 2.24 & $>97.5 \%$ \\
\hline Category 4 & 0.5 & 2.6 & $387 \%$ & 3.76 & $\sim 99.9 \%$ \\
\hline
\end{tabular}

pronounced sensitivity to changes in sea surface temperature. Forced by SSTs typical of a mid-range global warming scenario (SRES A1B), the strongest storms produced in the model became more intense (Figure 10). This is in agreement with independent studies from three other groups that have explored this issue using relatively high-resolution models $[13,16,17,39]$ Bengtsson 2007. Such intensification is also consistent with the theoretical notion of tropical cyclones as giant heat engines [40] and the changes in the model's climatology. An examination of the changes in large-scale features of the atmosphere relevant to tropical cyclones is revealing. The monthly mean windshear in the ACR and PCR (Figure 11) does not change significantly in the ensemble of future scenario runs compared to the AMIP simulation. Note that modeled wind shear is substantially higher than ERA40 reanalysis in the Atlantic hurricane season. Hence, the chances of the low wind shear conditions in the cyclogenesis regions necessary for intense storms do not change much in the future simulation. The total column water vapor (Figure 12) increases in the warmer integration, a consequence of the ability of warmer air to hold more water [6]. This implies that more latent heat energy would be available for tropical cyclones also supporting the notion that stronger storms are possible in the future simulation. Emanuel's [40] thermodynamical description of tropical cyclones as Carnot heat engines transporting energy from the surface to higher altitudes can be expressed by a maximum potential intensity (MPI) of surface winds and is straightforwardly calculated assuming ideal wind shear conditions. In Figure 13, the average July through November change in the maximum potential intensity (MPI) of tropical storm winds per degree warming is shown for the ensemble of climate change experiments and is comparable to the multi-model ensemble result calculated by Vecchi and Soden [41]. Changes in MPI are principally driven by changes in future SSTs which can vary a great deal between models. fvCAM2.2 exhibits an increase in MPI across most of the Northern Pacific similar in magnitude and pattern to the Vecchi and Soden multi-model average. In the small area of the northwestern Pacific where the multi-model average shows little change, fvCAM2.2 exhibits a decrease similar to another model as detailed by Xie et al. [42] but smaller in extent and magnitude. In the north Atlantic, a band of MPI decrease extending from Gibraltar towards the southwest 


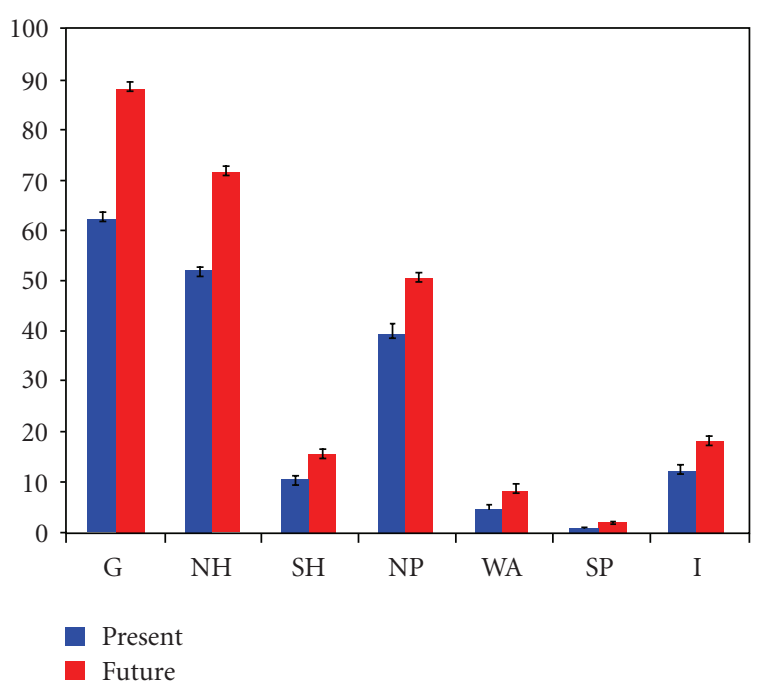

FIGURE 9: Average number of tropical storms with wind in excess of 33 knots during the August-November period simulated in fvCAM2.2. The "present" ensemble is forced with 1990-1999 sea surface conditions. The "future" ensemble is forced with sea surface conditions representative of the SRES A1B scenario at the end of the 21 st century. The error bars represent the inter-realization standard error for each ensemble. G: global, NH: Northern Hemisphere, SH: Southern Hemisphere, NP: North Pacific basin, NA: North Atlantic basin, SP: South Pacific basin, I: Indian Ocean.

divides two areas of MPI increase. This region of MPI decrease is similar in its east-west extent to the multi-model average but narrower in its north-south extent. In this regard, the present result resembles that of Xie et al. [42]. Because of these climatological changes in MPI, tropical storms forming under near ideal conditions of low wind shear and high moist instability would more likely undergo the rapid and explosive intensification typical of major storms in fvCAM2.2.

Unlike previous studies [13, 16, 17, 39] Bengtsson, 2007, fvCAM2.2 produced a larger total number of named tropical storms rather than less in every ocean basin with significant tropical cyclone activity when driven by warmer SSTs (Figure 9). In the Table 4 of the present paper, percent increases in the numbers of storms were greatest for the most intense storms produced (category 4 ) followed by the smallest storms tracked (tropical storm strength). Percent increases in the numbers of category 2 storms were the smallest and not as statistically significant. In the prior studies just cited, the calculations with warmer surface temperatures exhibited a reduction in the number of tropical storms. However, Kusunoki et al. [43] and Sugi et al. [44] find that despite a global decrease in the number of tropical cyclones, the number of tropical cyclones increases in the North Atlantic basin. Bengtsson et al. [13] suggests that a reduction in tropical cyclone number might be due to a slowing down of the large-scale tropical circulation and a resultant decrease in the number of initial disturbances capable of developing into full-scale tropical cyclones. Figure 14 shows the potential temperature for the tropical region $30 \mathrm{~S}-30 \mathrm{~N}$ averaged over August through November in the $0.5^{\circ} \times 0.625^{\circ}$

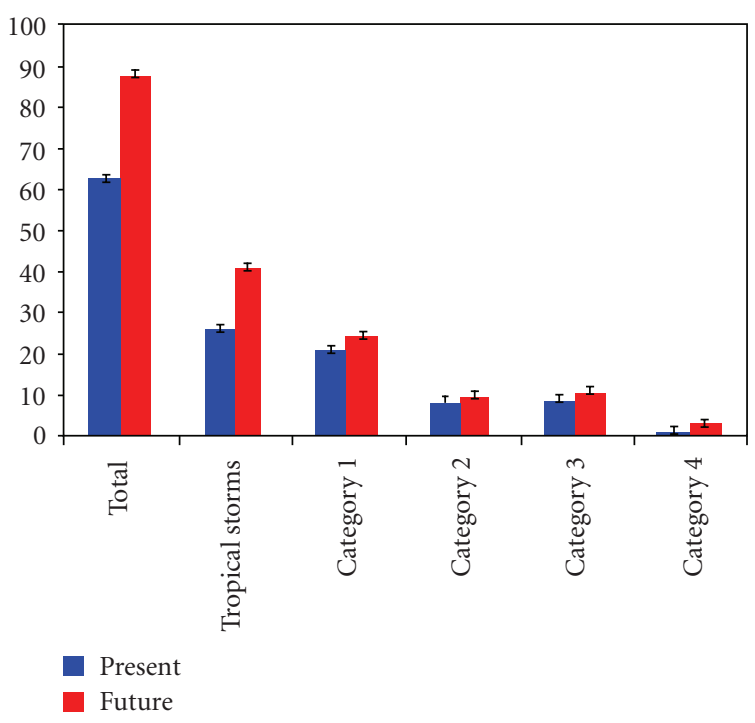

FIGURE 10: The average number of tropical storms across the globe during the August-November period as characterized by the SaffirSimpson scale simulated by fvCAM2.2. The "present" ensemble is forced with 1990-1999 climatological sea surface conditions. The "future" ensemble is forced with sea surface conditions representative of the SRES A1B scenario at the end of the 21st century. The error bars represent the inter-realization standard error for each ensemble.

configuration of fvCAM2.2. A less steep lapse rate in the simulation of the warmer future atmosphere, evident from the difference in the slopes of the two curves in Figure 14, indicates a more statically stable atmosphere than in the present day simulation. This figure is comparable to Figure 17 in Bengtsson et al. [13] and suggests that the change in static stability in fvCAM2.2 is similar to that seen in the ECHAM5 model, especially above $500 \mathrm{mb}$.

Zhao et al. $[18,45]$ show that in a different $50 \mathrm{~km}$ model that the difference between SSTs in the cyclogenesis regions and across the entire tropics controls the interannual variations in North Atlantic tropical storms. They also suggest that relative warming defined by this difference could be a factor in the number of future tropical storms. However, for this experiment, the August-September-October average "Atlantic relative SST, $\Phi_{\mathrm{NA}}$ " is $1.9 \mathrm{~K}$ in the present day configuration and $1.8 \mathrm{~K}$ in the end of 21 st century configuration. This small negative change in relative warming does not explain the North Atlantic tropical storm response of fvCAM2.2.

4.2. Comments on Future Directions. Both the model and the experimental design are flawed in a number of ways, undermining the confidence in these projections of future tropical cyclone activity. These flaws are not unique to this study and a frank discussion of them can guide future work in this important activity. The integration period for the climate change experiment was chosen to double the number of Atlantic hurricane seasons available for analysis. In hindsight, it would be interesting to include the complete 




(a)

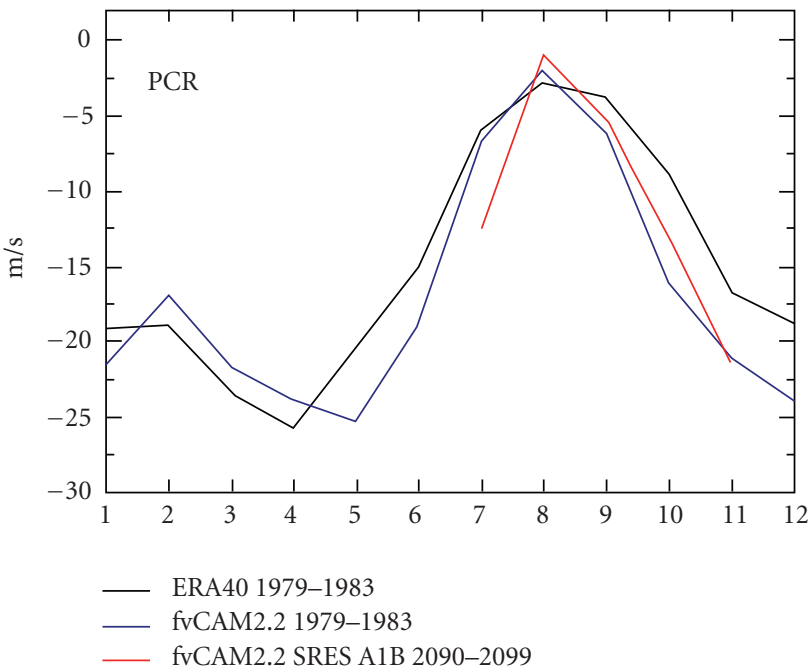

(b)

FIGURE 11: The monthly average wind shear $(\mathrm{m} / \mathrm{s})$ in the Atlantic (ACR) and Pacific (PCR) Cyclogenesis Regions. Wind shear is defined as the difference between zonal wind speed at $200 \mathrm{mb}$ and $850 \mathrm{mb}$. Black line: ERA40 reanalysis. Blue line: fvCAM2.2 $\left(0.5^{\circ} \times\right.$ $\left.0.625^{\circ}\right) 1979-1983$ average. Red line: fvCAM2.2 $\left(0.5^{\circ} \times 0.625^{\circ}\right)$ 2090-2099 July-November conditions (SRES A1B).

annual cycle so that southern hemisphere tropical cyclones were included in the study. Also, we feel that time slices of selected past and future periods would be more interesting than climatologically averaged integrations in that changes in interannual variability could be studied provided large enough ensembles could be generated.

The AMIP-style integration of fixed SST is a more significant limitation. Intense tropical storms can noticeably reduce the upper ocean temperatures. The infinite heat capacity ocean of the experiments discussed here cannot replicate this effect. A mixed layer ocean model coupled to the AGCM would be an improvement but a coupled ocean-atmosphere general circulation model could capture

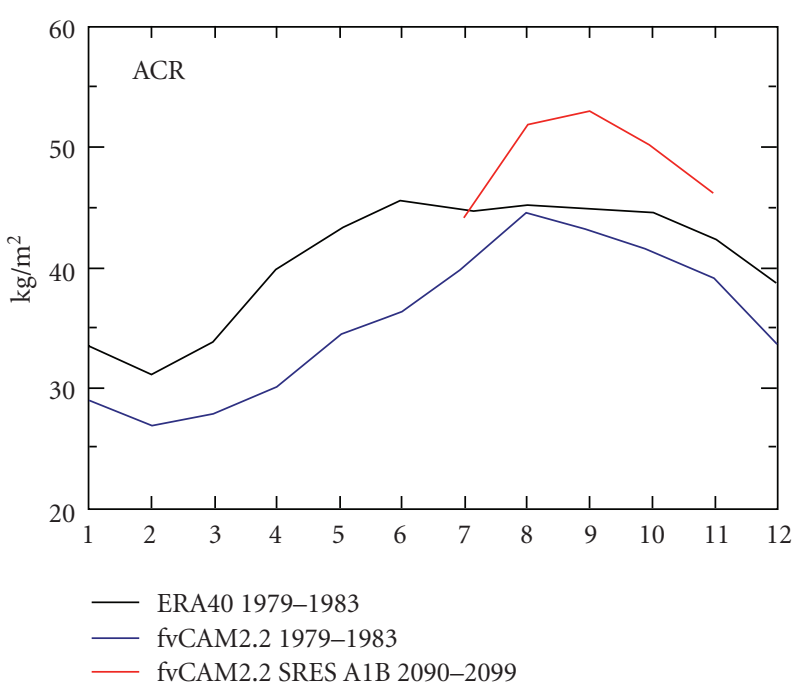

(a)

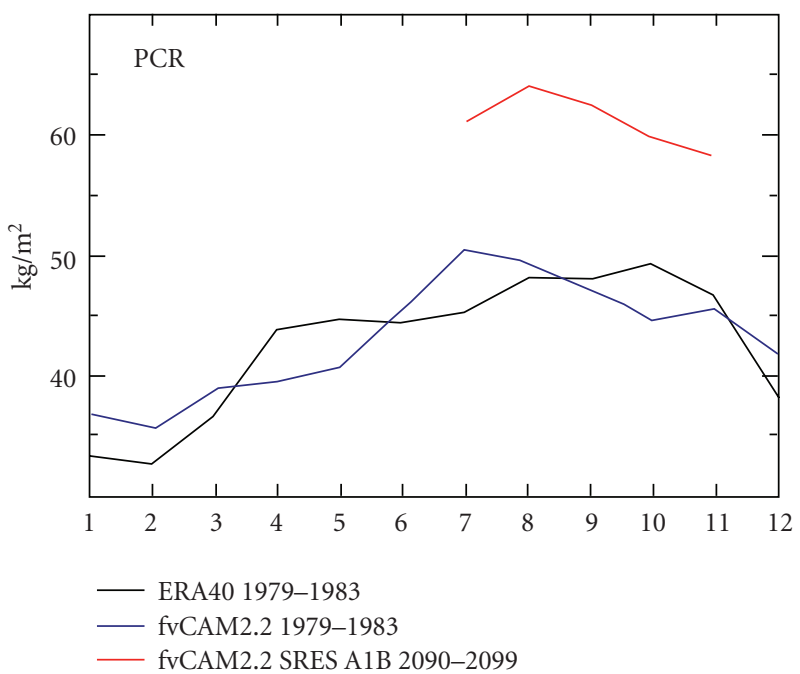

(b)

Figure 12: The monthly average total column integrated water vapor $\left(\mathrm{kg} / \mathrm{m}^{2}\right)$ in the Atlantic (ACR) and Pacific (PCR) Cyclogenesis Regions. Black line: ERA40 reanalysis. Blue line: fvCAM2.2 $\left(0.5^{\circ} \times\right.$ $\left.0.625^{\circ}\right)$ 1979-1983 average. Red line: fvCAM2.2 $\left(0.5^{\circ} \times 0.625^{\circ}\right)$ 2090-2099 July-November conditions (SRES A1B).

the upper ocean layers even more realistically. Spin-up of initial ocean conditions is made somewhat simpler than for typical century-scale integrations as the deep ocean layers do not play as large a role in decadal scale simulations.

The AMIP protocol defines transient forcing only at the surface. However, human induced changes to trace pollutants have a detectable in situ influence on the vertical structure of the atmosphere [46]. Single forcing couple climate model runs indicate that stratospheric ozone depletion tends to cool the stratosphere and heat the troposphere. This human induced effect tends to raise the tropopause height, effectively cooling the air temperature at this boundary. In Emanuel's idealized Carnot heat engine model of a perfect 


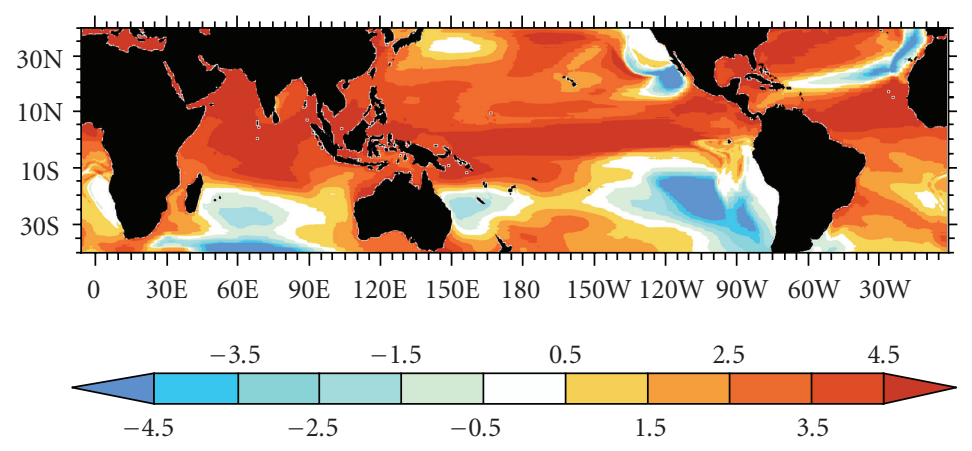

FIGURE 13: The change in maximum potential intensity (MPI) of surface $\left(10\right.$ meter) winds (knots $\left./{ }^{\circ} \mathrm{C}\right)$ calculated by Emanuel's Carnot heat engine theory in the fvCAM2.2 $\left(0.5^{\circ} \times 0.625^{\circ}\right)$ climate change experiment (SRES A1B). The results are averaged from July 1 to November 30 (JASON) to be comparable to Vecchi and Soden [41].

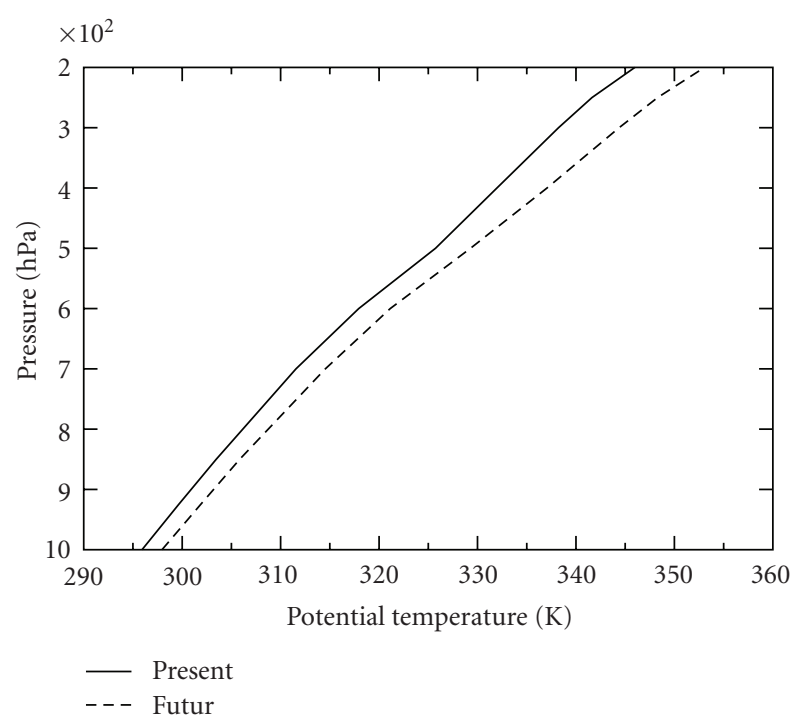

Figure 14: Potential temperature in the $0.5^{\circ} \times 0.625^{\circ}$ configuration of fvCAM2.2 $\left(0.5^{\circ} \times 0.625^{\circ}\right)$ for the tropical region $30 \mathrm{~S}-30 \mathrm{~N}$ averaged over August through November illustrating a change in the static stability of the simulated atmosphere.

hurricane [40], such a reduction in top of storm temperature raises the maximum potential wind intensity by making the engine more thermodynamically efficient. Greenhouse gas concentration changes have a similar effect on the vertical temperature profile that is even larger. Conversely, sulfate aerosols tend to increase the temperature of the stratosphere and decrease the temperature in the troposphere, lowering the tropopause height. Hence, increases in atmospheric sulfate aerosols have the opposite effect of stratospheric ozone depletion by lowering Emanuel's maximum potential intensity. The in situ change in the atmosphere's vertical structure due to trace pollutants also plays a role in the atmosphere's vertical static stability. The lack of changes in these pollutants in our climate change experiment and the associated change in radiative forcing may be a possible explanation for the increase in the number of weaker tropical cyclones compared to the decreases seen in other studies. An attempt to investigate the role of this radiative forcing by calculating the change in MPI in an ensemble of SRES A1B and twentieth century CCSM3.0 simulations was inconclusive. Despite more realistic radiative forcing, the CCSM3.0 MPI change does not resemble similar calculations from either the GFDL AM2.1 [42] or the multi-model average [41]. In fact, the fvCAM2.2 MPI change in Figure 13 shares more in common with these two previously published results than does the fully coupled model. However, MPI is not a measure of cyclogenesis and this exercise does not rule out the possibility that future changes in radiative forcing suppress the number of tropical cyclones. A related study by Yoshimura and Sugi [19] varied changes in greenhouse gas forcing and SST independently and found that each reduced the global number of tropical cyclones. Our results, which are similar to the SST variation half of the Yoshimura and Sugi [19] experiment, are at odds with their result. We did not explore the radiative forcing changes directly in this study.

The horizontal resolution necessary to capture the finest details of intense hurricanes in a global climate model is well beyond current computing capabilities. This study focused on a model with a grid spacing of about $50 \mathrm{~km}$ at the equator. Consistent with a conjecture by Bengtsson et al. [13], this resolution captured enough of the coarser characteristics of tropical cyclones to permit a reasonable description of storm statistics. However, the strongest storms in the simulation do not exceed Category 4 on the Saffir-Simpson intensity scale and are definitely weaker than the strongest storms in the real world. It is also likely that convergence of strong tropical storm intensity with resolution increases has not completed at $50 \mathrm{~km}$. Fortunately, computing technology continues to progress. We estimate that the fidelity of fvCAM could be doubled to approximately $25 \mathrm{~km}$ at the equator yet model integration time could be simulated 350 times faster than real time on 2048 processors of a CRAY XT4 [47]. A fully coupled version of CCSM with a $0.1^{\circ}$ ocean and sea ice model would require about twice as many processors and run at half the rate. For comparison, execution speeds of the numerous CCSM3.0 simulations prepared for the IPCC 
AR4 report averaged around 1600 times faster than real time. This would be a significant investment in computer resources but is certainly possible on existing and future machines.

There are large model dependencies in the literature regarding tropical cyclone simulation, especially in the ability to simulate intense storms $[13,16-18,39,45]$. Comparing these studies, it is clear that high horizontal resolution is not the only factor controlling tropical cyclone genesis and development in climate models [18]. A systematic investigation of parameterization differences would be another useful investment in computer resources and could lead to better simulation of tropical cyclone statistics.

\section{Conclusions}

We demonstrate that fvCAM2.2, a finite volume version of the Community Atmospheric Model, produces surprisingly realistic tropical cyclone statistics with essentially no tuning. In a $0.5^{\circ} \times 0.625^{\circ}$ configuration (approximately $50 \mathrm{~km}$ at the equator), the model has no difficulty producing Category 4 storms on the Saffir-Simpson intensity scale. The number and distribution of tropical cyclones is sensitive to horizontal resolution and has probably not converged at this grid size. A climate change experiment, based on an IPCC SRES A1B end of 21st century projection of sea surface temperatures, reveals that the change in Emanuel's Maximum Potential Intensity index (MPI) is consistent with other studies [40, 41], Xie et al. 2010. As in similar high-resolution climate change studies $[13,16,17,39]$, an increase in the number of intense tropical cyclones is projected by fvCAM2.2 with the strongest storms becoming more intense. This is expected based on thermodynamic considerations [4]. In contrast to these similar high-resolution studies, fvCAM2.2 produced more overall tropical cyclones, not less as the climate warms. The biggest percent increase occurred in the number of category 4 storms followed by the number of weak named tropical cyclones (wind speeds less than Category 1). The mechanisms for this difference in model behavior are unclear and further numerical experimentation is required. It is also clear that in order to have confidence in projections of future tropical cyclone activity, more high-resolution modeling studies must be performed by independent groups.

\section{Acknowledgments}

This work was performed under the auspices of the U.S. Department of Energy (DOE) by the Lawrence Berkeley National Laboratory (LBNL) under Contract no. DE-AC0376SF00098 (LBNL) and by the Lawrence Livermore National Laboratory under Contract DE-AC52-07NA27344 and with support from the DOE Earth System Modeling Program. The authors are grateful for advice from Joseph Sirutis (GFDL), Michael Fiorino (NOAA), and Benjamin Santer (LLNL). The authors thank the National Center for Energy Research (NERSC) for a generous preacceptance allocation of computational resources.

\section{References}

[1] P. J. Webster, G. J. Holland, J. A. Curry, and H.-R. Chang, "Atmospheric science: changes in tropical cyclone number, duration, and intensity in a warming environment," Science, vol. 309, no. 5742, pp. 1844-1846, 2005.

[2] W. M. Frank and G. S. Young, "The interannual variability of tropical cyclones," Monthly Weather Review, vol. 135, no. 10, pp. 3587-3598, 2007.

[3] G. J. Holland and P. J. Webster, "Heightened tropical cyclone activity in the North Atlantic: natural variability or climate trend?" Philosophical Transactions of the Royal Society A, vol. 365, no. 1860, pp. 2695-2716, 2007.

[4] K. Emanuel, "Increasing destructiveness of tropical cyclones over the past 30 years," Nature, vol. 436, no. 7051, pp. 686688, 2005.

[5] J. B. Elsner, J. P. Kossin, and T. H. Jagger, "The increasing intensity of the strongest tropical cyclones," Nature, vol. 455, no. 7209, pp. 92-95, 2008.

[6] B. D. Santer, T. M. L. Wigley, P. J. Gleckler et al., "Forced and unforced ocean temperature changes in Atlantic and Pacific tropical cyclogenesis regions," Proceedings of the National Academy of Sciences of the United States of America, vol. 103, no. 38, pp. 13905-13910, 2006.

[7] N. P. Gillett, P. A. Stott, and B. D. Santer, "Attribution of cyclogenesis region sea surface temperature change to anthropogenic influence," Geophysical Research Letters, vol. 35, no. 9, Article ID L09707, 2008.

[8] W. M. Gray, "Hurricanes: their formation, structure and likely role in the tropical circulation," in Meteorology over the Tropical Oceans, Royal Meterological Society, Bracknell, UK, August 1979.

[9] S. J. Camargo, A. H. Sobel, A. G. Barnston, and K. A. Emanuel, "Tropical cyclone genesis potential index in climate models," Tellus, Series A, vol. 59, no. 4, pp. 428-443, 2007.

[10] C. Covey, K. M. AchutaRao, S. J. Lambert, and K. E. Taylor, "Intercomparison of present and future climates simulated by coupled ocean-atmosphere GCMs," Program for Climate Model Diagnosis and Intercomparison Report 66, 2000, Lawrence Livermore National Laboratory UCRL-ID-140325.

[11] L. Bengtsson, M. Botzet, and M. Esch, "Hurricane-type vortices in a general circulation model," Tellus, Series A, vol. 47, no. 2, pp. 175-196, 1995.

[12] L. Bengtsson, M. Botzet, and M. Esch, "Will greenhouse gas-induced warming over the next 50 years lead to higher frequency and greater intensity of hurricanes?" Tellus, Series A, vol. 48 , no. 1 , pp. $57-73,1996$.

[13] L. Bengtsson, K. I. Hodges, M. Esch et al., "How may tropical cyclones change in a warmer climate?" Tellus, Series A, vol. 59, no. 4, pp. 539-561, 2007.

[14] T. R. Knutson and R. E. Tuleya, "Impact of $\mathrm{CO}_{2}$-induced warming on simulated hurricane intensity and precipitation: sensitivity to the choice of climate model and convective parameterization," Journal of Climate, vol. 17, no. 18, pp. 3477-3495, 2004.

[15] T. R. Knutson, J. J. Sirutis, S. T. Garner, I. M. Held, and R. E. Tuleya, "Simulation of the recent multidecadal increase of Atlantic hurricane activity using an 18-km-grid regional model," Bulletin of the American Meteorological Society, vol. 88, no. 10, pp. 1549-1565, 2007.

[16] M. A. Bender, T. R. Knutson, R. E. Tuleya, et al., "Modeled impact of anthropogenic warming on the frequency of intense Atlantic hurricanes," Science, vol. 327, no. 5964, pp. 454-458, 2010. 
[17] K. Oouchi, J. Yoshimura, H. Yoshimura, R. Mizuta, S. Kusunoki, and A. Noda, "Tropical cyclone climatology in a global-warming climate as simulated in a $20 \mathrm{~km}$-mesh global atmospheric model: frequency and wind intensity analyses," Journal of the Meteorological Society of Japan, vol. 84, no. 2, pp. 259-276, 2006.

[18] M. Zhao, I. M. Held, S.-J. Lin, and G. A. Vecchi, "Simulations of global hurricane climatology, interannual variability, and response to global warming using a 50-km resolution GCM," Journal of Climate, vol. 22, no. 24, pp. 6653-6678, 2009.

[19] J. Yoshimura and M. Sugi, "Tropical cyclone climatology in a high-resolution AGCM-impacts of SST warming and $\mathrm{CO}_{2}$ increase," Scientific Online Letters on the Atmosphere, vol. 1, pp. 133-136, 2.

[20] S.-J. Lin and R. B. Rood, "Multidimensional flux-form semiLagrangian transport schemes," Monthly Weather Review, vol. 124, no. 9, pp. 2046-2070, 1996.

[21] S.-J. Lin and R. B. Rood, "An explicit flux-form semiLagrangian shallow-water model on the sphere," Quarterly Journal of the Royal Meteorological Society, vol. 123, no. 544, pp. 2477-2498, 1997.

[22] S.-J. Lin, "A finite-volume integration method for computing pressure gradient force in general vertical coordinates," Quarterly Journal of the Royal Meteorological Society, vol. 123, no. 542, pp. 1749-1762, 1997.

[23] S.-J. Lin, “A 'vertically Lagrangian' finite-volume dynamical core for global models," Monthly Weather Review, vol. 132, no. 10, pp. 2293-2307, 2004.

[24] W. L. Gates, "AMIP: the Atmospheric Model Intercomparison Project," Bulletin-American Meteorological Society, vol. 73, no. 12, pp. 1962-1970, 1992.

[25] K. Taylor, D. Williamson, and F. Zwiers, "The sea surface temperature and sea-ice concentration boundary conditions for AMIP II simulations," PCMDI Report 60, 2000, Lawrence Livermore National Laboratory Report UCRL-MI-123395.

[26] W. D. Collins, P. J. Rasch, B. A. Boville et al., "The formulation and atmospheric simulation of the Community Atmosphere Model version 3 (CAM3)," Journal of Climate, vol. 19, no. 11, pp. 2144-2161, 2006.

[27] A. A. Mirin and W. B. Sawyer, "A scalable implementation of a finite-volume dynamical core in the community atmosphere model," International Journal of High Performance Computing Applications, vol. 19, no. 3, pp. 203-212, 2005.

[28] C. E. Leith, "Climate response and fluctuation dissipation," Journal of the Atmospheric Sciences, vol. 32, no. 10, pp. 20222026, 1975.

[29] A. Arakawa and V. R. Lamb, " Computational design of the basic dynamical processes of the UCLA general circulation model," in Methods in Computational Physics, J. Chang, Ed., vol. 17, pp. 173-265, Academic Press, New York, NY, USA, 1977.

[30] P. J. Klotzbach and W. M. Gray, "Twenty-five years of Atlantic basin seasonalhurricane forecasts (1984-2008)," Geophysical Research Letters, vol. 36, Article ID L09711, 5 pages, 2009.

[31] P. J. Klotzbach and W. M. Gray, The Tropical Meterology Project, http://hurricane.atmos.colostate.edu/Forecasts/.

[32] T. E. Larow, Y.-K. Lim, D. W. Shin, E. P. Chassignet, and S. Cocke, "Atlantic basin seasonal hurricane simulations," Journal of Climate, vol. 21, no. 13, pp. 3191-3206, 2008.

[33] C. D. Hoyos, P. A. Agudelo, P. J. Webster, and J. A. Curry, "Deconvolution of the factors contributing to the increase in global hurricane intensity," Science, vol. 312 , no. 5770, pp. 94 97, 2006.
[34] N. Nakicenovic and R. Swart, Eds., IPCC Special Report on Emissions Scenarios, 2000, http://www.grida.no/climate/ ipcc/emission/.

[35] G. A. Meehl, C. Covey, T. Delworth et al., "The WCRP CMIP3 multimodel dataset: a new era in climatic change research," Bulletin of the American Meteorological Society, vol. 88, no. 9, pp. 1383-1394, 2007.

[36] T. M. Smith and R. W. Reynolds, "A global merged landair-sea surface temperature reconstruction based on historical observations (1880-1997)," Journal of Climate, vol. 18, no. 12, pp. 2021-2036, 2005.

[37] N. A. Rayner, P. Brohan, D. E. Parker et al., "Improved analyses of changes and uncertainties in sea surface temperature measured in Situ since the mid-nineteenth century: the HadSST2 dataset," Journal of Climate, vol. 19, no. 3, pp. 446469, 2006.

[38] K. A. Emanuel, "The dependence of hurricane intensity on climate," Nature, vol. 326, no. 6112, pp. 483-485, 1987.

[39] T. R. Knutson, J. J. Sirutis, S. T. Garner, G. A. Vecchi, and I. M. Held, "Simulated reduction in Atlantic hurricane frequency under twenty-first-century warming conditions," Nature Geoscience, vol. 1, no. 6, pp. 359-364, 2008.

[40] K. A. Emanuel, "Sensitivity of tropical cyclones to surface exchange coefficients and revised steady-state model incorporating eye dynamics," Journal of the Atmospheric Sciences, vol. 52, no. 22, pp. 3969-3976, 1995.

[41] G. A. Vecchi and B. J. Soden, "Effect of remote sea surface temperature change on tropical cyclone potential intensity," Nature, vol. 450, no. 7172, pp. 1066-1070, 2007.

[42] S.-P. Xie, C. Deser, G. A. Vecchi, J. Ma, H. Teng, and A. T. Wittenberg, "Global warming pattern formation: sea surface temperature and rainfall," Journal of Climate, vol. 23, no. 4, pp. 966-986, 2010.

[43] S. Kusunoki, J. Yoshimura, H. Yoshimura, R. Mizuta, K. Oouchi, and A. Noda, "Global warming projection by an atmospheric global model with $20-\mathrm{Km}$ grid," Journal of Disaster Research, vol. 3, pp. 4-14, 2008.

[44] M. Sugi, H. Murakami, and J. Yoshimura, "A reduction in global tropical cyclone frequency due to global warming," Scientific Online Letters on the Atmosphere, vol. 5, pp. 164-167, 2009.

[45] M. Zhao, I. M. Held, and G. A. Vecchi, "Retrospective forecasts of the hurricane season using a global atmospheric model assuming persistence of SST anomalies," Monthly Weather Review. In press.

[46] B. D. Santer, M. F. Wehner, T. M. L. Wigley et al., "Contributions of anthropogenic and natural forcing to recent tropopause height changes," Science, vol. 301, no. 5632, pp. 479-483, 2003.

[47] L. Oliker, J. Carter, M. Wehner et al., "Leading computational methods on scalar and vector HEC platforms," in Proceedings of the ACM/IEEE Supercomputing Conference (SC '05), pp. 6274, November 2005. 

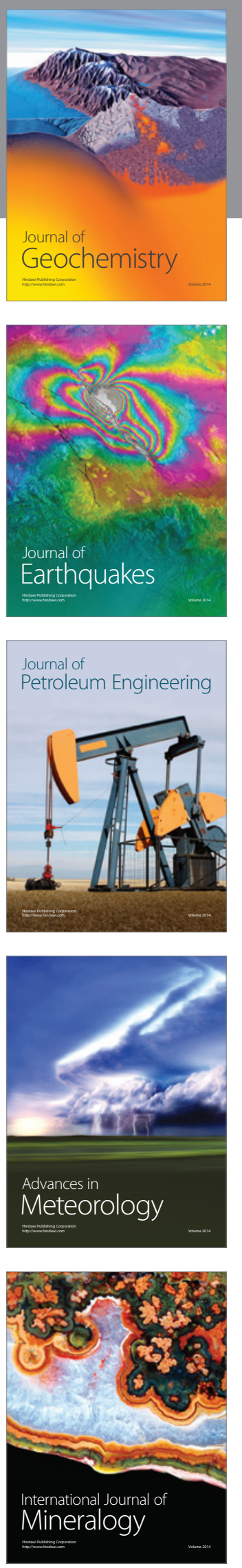
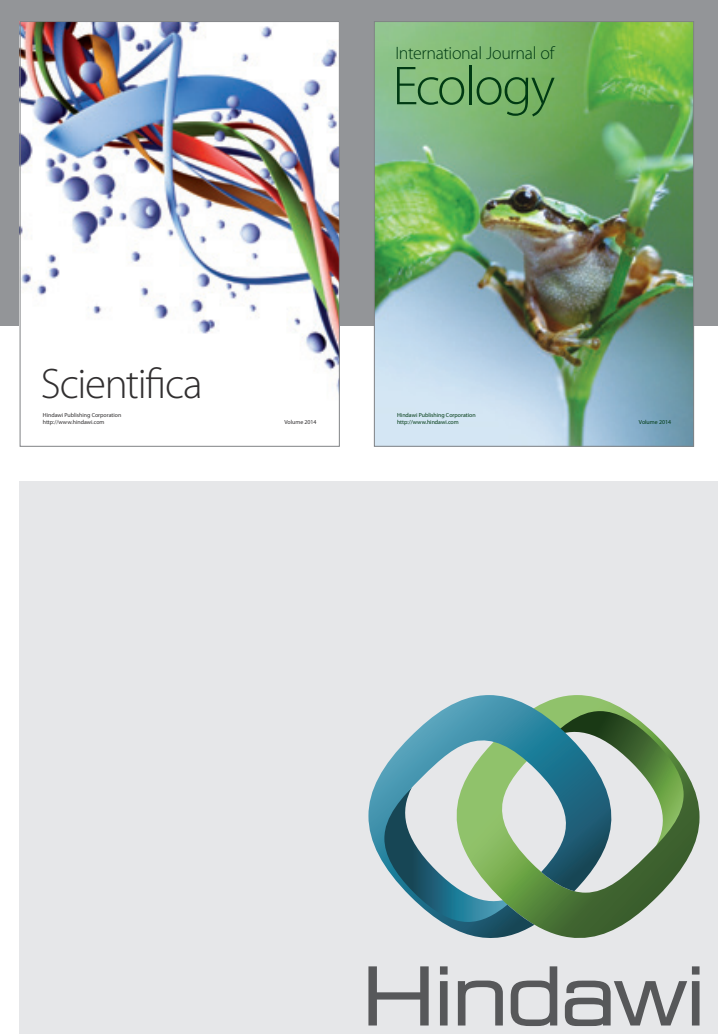

Submit your manuscripts at http://www.hindawi.com

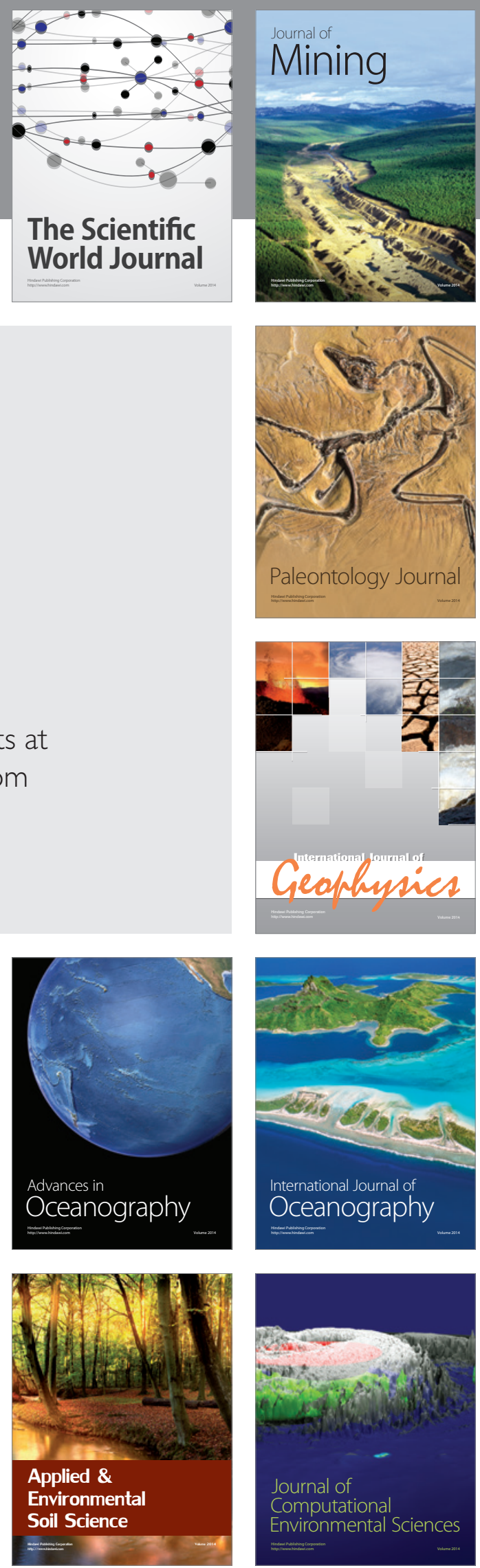